\title{
Evolution of Radio Frequency Identification (RFID) in Agricultural Cold Chain Monitoring: A Literature Review
}

\author{
Bahareh Mosadegh Sedghy ${ }^{1}$ \\ ${ }^{1}$ Dhillon School of Business, University of Lethbridge, Lethbridge, Canada \\ Correspondence: Bahareh Mosadegh Sedghy, Dhillon School of Business, University of Lethbridge, Lethbridge, \\ Canada. Tel: 001-403-329-518. E-mail: bahareh.mosadeghsedg@uleth.ca
}

Received: December 2, 2018

Accepted: January 4, 2019

Online Published: February 15, 2019

doi:10.5539/jas.v11n3p43

URL: https://doi.org/10.5539/jas.v11n3p43

\begin{abstract}
Radio Frequency Identification (RFID) is a technology providing considerable opportunities to improve quality control for perishable foods. Over the past decade, a significant improvement in RFID application has been observed in cold chain monitoring. The aim of this paper is to, first, demonstrate the role of RFID in improving the monitoring of the agricultural products cold chain. Particular focus is placed on the specifications of RFID and its advantages, which makes its application appealing in food temperature monitoring. Second, this paper aims to provide an overview of RFID developments in cold chain monitoring. For this purpose, we conduct a review of the literature throughout 2004-2018 citing the challenges of this technology's practical implementation in temperature monitoring of perishables, and provide the solutions presented in the literature for each limitation. This survey would be beneficial for those involved in food distribution, as it offers approaches for overcoming the limitations of RFID, making its application more advantageous.
\end{abstract}

Keywords: cold chain, food sector, Radio Frequency Identification (RFID), refrigerated vehicles, temperature-controlled supply chain, temperature monitoring

\section{Introduction}

Supply chain management (SCM) is the "management and control of all materials and information in the logistics process from acquisition of raw materials to delivery to the end user" (Aitken, 1998). Agricultural SCM is a complicated process. Agricultural commodities have to undergo a series of operations including harvesting, threshing, winnowing, bagging, transportation, storage, processing, and exchange before they reach the market (Somashekhar et al., 2014). Advancements in information system technology have had a remarkable impact on agricultural SCM, helping it to evolve and leading to the enhancement of its logistical processes.

In an environment as complex as a supply chain, interfaces between information systems across the supply chain are necessary. With technological advancements in this area, supply chain partners can now work in close coordination to improve chain-wide efficiency and effectiveness. For the information systems to communicate proper data across the supply chain, automatic identification technologies are required. Some of the most adopted technologies include RFID, barcoding, Global Positioning System (GPS), and wireless sensor network (WSN), which aim to increase the efficiency of the supply chain network and ensure reliable information sharing. These technologies provide greater visibility by providing real-time information throughout the supply chain, allowing adaptability to market changes.

Among automated identification technologies, RFID has been central in revolutionizing agricultural supply chain networks. Within the past few years, RFID has shifted from inconspicuousness to mainstream application. RFID provides wireless identification of objects by remotely detecting electromagnetic signals. A classic RFID model has three components: a tag; a reader, which collects data; and database and information management software (Lee et al., 2006). Radio signals are emitted from the reader to activate the tag and allow the data to be received. Through the reader, communication is established between the tag and the transceiver. The RFID tag, when found in an electromagnetic zone, detects the activation signal of the reader. The reader then decrypts the data encrypted in the integrated circuit of the tag and transfers the data for processing. RFID tags can be active, passive, or semi-passive. Passive and semi-passive RFID tags send their data by reflection or modulation of the electromagnetic field that was emitted by the reader (Ruiz-Garcia et al., 2009). 


\subsection{RFID Application in the Agricultural Supply Chain}

Automated identification technology has been used for decades at different levels and in a diversity of applications in the agricultural supply chain. However, the utilization of RFID technology in various sectors of the agri-food industry has gained considerable attention in recent years.

Due to its ability to identify and categorize different commodities, this technology is mostly applied for the traceability of agricultural products (Jones et al., 2004; Angeles, 2005; Twist, 2005; Attaran, 2007; Ngai \& Riggins, 2008; Sarac et al., 2010). Traceability is a crucial factor for the agri-food industry, as it provides an important criterion for food product quality and safety (Opara, 2003).

RFID technology is also benefiting precision agriculture, where the development of RFID applications makes it possible to increase efficiencies, productivity, and profitability. The real-time information gathered from the fields can also provide a solid basis for farmers to adjust their strategies at any time (Ruiz-Garcia \& Lunadei, 2011).

Monitoring the cold chain of perishable foods is another application of RFID in the agri-food industry. Temperature management is a primary concern in the food industry because temperature can affect the shelf life and quality of agricultural products. RFID can record time-temperature information at constant intervals and provide data for the temperature fluctuations experienced by a product (Kumari et al., 2015).

RFID may also lead to greater benefits for agricultural SCM through reducing inventory losses (Sarac et al., 2010). Chappell et al. (2003) cite spoilage as one of the causes of inventory inaccuracies with perishable products. RFID technology, with its ability to monitor temperature and predict the shelf life of perishables, could improve inventory management for agricultural products.

Among RFID's applications in the agricultural sector, this study focuses on the application of RFID in cold chain monitoring. Since the majority of agricultural products can be considered perishable, a failure in the cold chain can result in excessive ripening, weight loss, softening, color and texture changes, physical degradation, bruising, and attacks by rot and molds. These factors affect the freshness, desirability, and marketability of agricultural products (Jedermann et al., 2009). Therefore, investigation into improvements to monitoring the cold chain for agricultural products can lead to waste reduction, thus increasing the profitability of agri-businesses.

This paper aims to demonstrate the role of RFID in improving agricultural products cold chain monitoring, and to provide an overview of developments in RFID application in monitoring the cold chain for perishables. For this purpose, we conduct a review of the literature on this application of RFID technology throughout 2014-2018, focusing on the advantages and disadvantages of its application. Finally, our study provides the solutions suggested in the literature for the various limitations of RFID application.

Section two of this paper explains the research methodology. Section three gives an extensive review of previous studies on the application of RFID in monitoring the cold chain for different agricultural products throughout 2004-2018, while highlighting the advantages and disadvantages of the technology's adoption. The paper concludes by summarizing (Tables 1 and 2) the various opportunities and challenges arising from RFID application in monitoring the cold chain for agricultural products, and reviewing and presenting coping mechanisms for the challenges. Then, based on these mechanisms, we discuss the evolution of RFID application in monitoring the agricultural products cold chain.

\section{Methodology}

The main objective of this paper is to provide an overview of RFID developments in cold chain monitoring, while identifying the existing challenges of RFID implementation in monitoring the cold chain for perishable products, and distinguishing solutions to these challenges. For this purpose, we review challenges of RFID implementation in monitoring the cold chain for agricultural products cited by scholars and also provide solutions mentioned in literature to each challenge. This kind of review demonstrates the evolution of RFID in the food sector over time.

This research is a bibliographic study and the process consisted of reviewing a total of 100 scholarly studies from refereed publications (including journal articles, book chapters, and theses) from 2004, since the application of RFID in refrigerated vehicles was first proposed that year. The publications were identified through computer-aided searches of renowned databases, and the articles found using keywords such as "temperature management and RFID", "cold chain monitoring and RFID", "transport and RFID", or "shelf life and RFID," and selected according to the following two criteria:

(1) It must contain explanations of RFID implementation in monitoring the cold chain for various agricultural products. 
(2) It must describe the advantages and disadvantages of RFID implementation in agricultural cold chain monitoring and preferably some suggestions to cope with the disadvantages.

The review is structured in two parts: (1) the advantages of RFID, which encourage its adoption in the temperature monitoring of perishables, and (2) its limitations and the suggestions for coping with these cited in the literature (where one exists).

\section{Monitoring the Cold Chain for Perishable Foods by Means of RFID: Review of Literature}

Perishable food has a considerable wastage rate. Globally, 1.3 billion tons of food are wasted every year (Buchner et al., 2012). The root cause of such a loss has been linked to insufficient temperature control (Pang et al., 2011). Low temperatures cause freezing damage, while too high a temperature has the potential to increase the rate of enzymatic and/or product spoilage (Badia-Melis et al., 2018). Fresh foods need to be stored and transported in a temperature-controlled environment to maintain or even improve their quality (Thakur \& Foras, 2015). Controlling the temperature of perishable foods is beneficial for supply chain partners - it can strengthen the confidence of consumers and enhance the partners' reputation for supplying high-quality food (Kim et al., 2016; Jedermann et al., 2009).

Some of the temperature monitoring systems used in the cold chain, such as strip chart recorders and temperature data loggers, which can follow the flow of products during storage and transport, are usually expensive and not automated (thus manual inspections are required), and they cannot provide a history of temperature data to which problems occurring in the cold chain can be traced. For these reasons, the use of these systems is limited to only some functions of the cold chain or to only a few types of products (Abad et al., 2009).

RFID is an emergent technology implemented across the food supply chain (Badia-Melis et al., 2016). "It can keep a record of the product's temperature history and provide accurate localized measurement results through an unbroken calibration to meet accepted standards" (Opara, 2003). RFID tags can be installed on the delivery item during the distribution process and used for automatically identifying the items based on the unique identifier assigned to each tag. By combining the information transmitted from RFID and temperature sensors, one can relate items with the environmental conditions (Michael \& McCathie, 2005; Amador et al., 2009; Amador \& Edmond. 2010; Kim et al., 2016).

\subsection{Advantages of RFID Application in Monitoring the Cold Chain of Perishables}

The use of wireless sensors including RFID in refrigerated vehicles was proposed originally by Qingshan et al. (2004). Such vehicles can host a variety of sensors to detect, identify, log, and communicate what happens during the product's journey, with the sensors monitoring the status of perishable products during transportation. One of the most prominent characteristics of RFID, which favors its application in cold chain monitoring, is the ability of RFID tags to work even in harsh conditions (such as in a temperature of minus 40 degrees centigrade) (Michael \& McCathie, 2005; Abad et al., 2009).

Following the proposal of 2004, several researchers investigated the application of RFID in monitoring the cold chain for perishables and found significant advantages for RFID adoption in temperature monitoring. According to Gras (2006), implementing RFID in the transport system offers the potential to manage issues in the supply chain through automatic identification. In other words, RFID does not entail manual scanning, and provides data remotely and continuously (see Table 1 for references). This characteristic leads to a decrease in labor cost and alleviates the human error that occurs with manual systems (Table 1).

On the other hand, automatic identification and remote data collection by RFID provide the possibility of both saving time and real-time quality control. Hundreds of RFID tags can be downloaded into and read from a computer at one time (Table 1), which could lead to a decrease in shipment confirmation time (Gras, 2006). Furthermore, while the large memory of RFID systems permits the collection of huge amounts of temperature data, these data can be recovered and read quickly (Table 1). This permits the collection of real-time information on the quality status of the product, and favors the application of RFID in food cold chain monitoring, which requires real-time decision-making (Table 1). Several researchers have taken advantage of the real-time temperature data provided by RFID. Li et al. (2006) proposed an innovative planning model to optimize perishable product allocations from manufacturers to distributors and retailers. The 2008 Olympic Games in Beijing also benefited from RFID application in the food sector. The temperature of the food storage compartments of all vehicles transporting food served at the Games was real-time monitored, which ensured the safety of the transported foods (Wu et al., 2010). Chen and Shaw (2011) and Zhang et al. (2018) benefited from the advantage of RFID in providing real-time temperature data, and proposed a real-time temperature control mechanism for agricultural products. Trebar et al. (2015) tapped into the potential of RFID to define the optimal cooling materials for fish 
packaging. Besides this, Zhou and Chakrabartty (2017) benefited from the advantage offered by RFID in providing continuous information for their study on using the continuous integration and storage of information as a time-temperature indicator.

Another advantage of the RFID system is the technology's quick instrumentation (Amador et al., 2009).

In addition, continuous temperature control and close temperature readings of perishables (by embedding temperature sensors within the loads) (Ruiz-Garcia et al., 2008) enable RFID to trace any problem arising throughout the product's journey (Ogasawara \& Yamasaki, 2006; Erdem et al., 2008). In addition, RFID provides a means to identify a defective product, thus helping to quicken reactions to any quality problem (Regattieri et al., 2007; Trebar et al., 2011) and to prevent the recall of products and associated costs (Kumar \& Budin, 2006). The ability of RFID tags to provide non-cumulative information can be considered another of RFID's advantages (Lorite et al., 2017), and this, accompanied by RFID's ability to provide real-time information, can lead to efficient risk management in cold chains, as both are beneficial for risk identification and response steps (Kim et al., 2016).

The real-time and continuous information provided by the RFID system can be also used in determining the freshness of perishables. According to Grunow and Piramuthu (2013), RFID provides an advantage in estimating the shelf life of perishables, as it is able to provide more information on the quality of products than the expiration date provides. Hertog (2006), Pop et al. (2009), Jedermann et al. (2009), and Badia-melis et al. (2016), benefiting from the temperature data provided by RFID, studied the effects of temperature change on the quality of perishables.

Some authors argue that RFID could contribute to an increase in transparency in the agricultural supply chain (Table 1). Focusing on the role of temperature indicators in supply chain transparency, Lorite et al. (2017) argued that time-temperature indicators provide only a cumulative indication of cargo temperatures. With the aim of providing non-cumulative information, the authors suggested the integration of RFID into a simple critical temperature indicator (CTI).

RFID application also provides some economic benefits. Alleviating the cost of a PC connection (Note 1). (Ogassawara \& Yamasaki, 2006; Tingman et al., 2010), increasing sales by reducing product loss (Estrada-Flores \& Tanner, 2008; Sarac et al., 2010), reducing labour cost, reducing inventory, and improving return on investment (Estrada-Flores \& Tanner, 2008) are some of the direct benefits of RFID implementation in perishable product supply chains. The reusability of tags and readers, which makes the application of RFID in the food industry cost-effective, adds to the direct benefits of RFID application in temperature monitoring (Ting, 2013; Aung \& Chang, 2014). On the other hand, improved consumer satisfaction can be considered an example of the indirect and non-financial benefits of the RFID system, and can increase direct benefits later (Sarac et al., 2010). Some authors have investigated the economic benefits of RFID application in cold chain monitoring. Hong et al. (2011) confirmed a positive profit from RFID application in a chain of convenience stores in Taiwan after years 3 and 4. The results of a study by Ketzenburg et al. (2015) indicated that significant value of information could be generated by the application of RFID in monitoring the cold chain for perishables through decreased product spoilage.

Based on the advantages cited in the literature of RFID application in monitoring the temperature of perishables, Kumari et al. (2015) and Badia-Melis et al. (2018) concluded that RFID provides significant value added for the agri-food industry, as it results in a more efficient supply chain. 
Table 1. Advantages of RFID application in agricultural cold chain monitoring

\begin{tabular}{|c|c|}
\hline Author & Advantage \\
\hline \multicolumn{2}{|l|}{ Time saving } \\
\hline Raza et al., 1999; Regattieri et al., 2007; Amador et al., 2009 & Rapid data recovery \\
\hline $\begin{array}{l}\text { Michael and McCathie, 2005; Narsing, 2005; Abad et al., 2009; Amador } \\
\text { et al., 2009; Raab et al., 2011; Aung and Chang, } 2014\end{array}$ & Ability to download and read many tags at one time \\
\hline Amador et al., 2009 & Quick instrumentation \\
\hline \multicolumn{2}{|l|}{ Data collection } \\
\hline $\begin{array}{l}\text { Kärkkäinen, 2005; Michael and McCathie, 2005; Li et al., 2006; Erdem } \\
\text { et al., 2008; Jedermannet al., 2008; Chen and Chaw, 2011; Raab et al., } \\
\text { 2011; Badia-Melis et al., } 2016\end{array}$ & Providing real-time information \\
\hline $\begin{array}{l}\text { Gras, 2006; Ogasawara and Yamasaki, 2006; Regattieri et al., 2007; } \\
\text { Montanari, 2008; Abad et al., 2009; Amador et al., 2009; Yan and lee, } \\
\text { 2009; Laniel and Edmond, 2010; Luo et al., 2010; Raab et al., 2011; } \\
\text { Trebar et al., 2011; Aung and Chang, 2014; Heising et al., } 2014\end{array}$ & Automatic identification and ability to collect data remotely \\
\hline Regattieri et al., 2007; Raab et al., 2011; Kang et al., 2012 & Continuous control of environmental temperature \\
\hline Lorit et al., 2017 & Providing non-cumulative information in critical points \\
\hline \multicolumn{2}{|l|}{ Risk management } \\
\hline Ogasawara and Yamasaki, 2006; Erdem et al., 2008 & Ability to trace cargo problems \\
\hline $\begin{array}{l}\text { Hertog, 2006; Pop et al., 2009; Jedermann et al., 2009; Grunow and } \\
\text { Piramuthu, } 2013\end{array}$ & $\begin{array}{l}\text { Providing information that can be used to determine the shelf } \\
\text { life of perishables }\end{array}$ \\
\hline Regattieri et al., 2007; Trebar et al., 2011 & Providing the means to identify a defective product \\
\hline Kim et al., 2016 & Enabling quick response to risks \\
\hline \multicolumn{2}{|l|}{ Structure } \\
\hline Michael and McCathie, 2005; Abad et al., 2009 & Good resistance to humidity and other environmental conditions \\
\hline $\begin{array}{l}\text { Montanari, 2008; Abad et al., 2009; Amador et al., 2009; Yan and Lee, } \\
\text { 2009; Heising et al., } 2014\end{array}$ & $\begin{array}{l}\text { - Ability to integrate physical and chemical sensors to associate } \\
\text { environmental conditions with tags }\end{array}$ \\
\hline Ruiz-Garcia et al., 2008 & $\begin{array}{l}\text { - Providing closer readings of perishables by embedding } \\
\text { temperature sensors within the load }\end{array}$ \\
\hline Montanari, 2008; Abad et al., 2009; Aung and Chang, 2014 & Large memory size \\
\hline \multicolumn{2}{|l|}{ Economic benefits } \\
\hline $\begin{array}{l}\text { Asif, 2005; Michael and McCathie, 2005; Thompson et al., 2005; } \\
\text { Ogasawara and Yamasaki, 2006; Estrada-Flores and Tanner, 2008; Yan } \\
\text { and Lee, 2009; Ruiz-Garcia and Lunadei, } 2010\end{array}$ & Reducing human error and labour cost \\
\hline Kumar and Budin, 2006 & Preventing product recalls \\
\hline Ogasawara and Yamasaki, 2006; Tingman et al., 2010 & $\begin{array}{l}\text { - } \quad \text { Reducing costs by collecting data independently without } \\
\text { connection to a PC }\end{array}$ \\
\hline Estrada-Flores and Tanner, 2008 & $\begin{array}{ll}\text { - } & \text { Reducing shrinkage } \\
\text { - } & \text { Reducing inventory } \\
\text { - } & \text { Improving the return on investment }\end{array}$ \\
\hline Estrada-Flores and Tanner, 2008; Sarac et al, 2010 & Increasing sales \\
\hline $\begin{array}{l}\text { Estrada-Flores and Tanner, 2008; Ruiz-Garcia and Lunadei, 2010; } \\
\text { Trebar et al., 2011; Ting, 2013; Lorite et al., } 2017\end{array}$ & Increasing supply chain transparency \\
\hline Ting, 2013; Aung and Chang, 2014 & Reversible tags \\
\hline Kumari et al., 2015 & Reducing costs by providing more efficient supply chain control \\
\hline Ketzenburg et al., 2015 & Providing significant value of information \\
\hline Badia-Melis et al., 2018 & Demonstrating significant value added for the agri-food industry \\
\hline
\end{tabular}

\subsection{Limitations of RFID Application in Monitoring the Cold Chain of Perishables and Their Solutions}

The vast potential of RFID in cold chain monitoring has led researchers to take advantage of the technology's benefits in their studies and to strive to find solutions for its limitations. Over time, these efforts have led to the technology's evolution. In this study, we categorize the limitations found in the literature as organizational, technical, and those related to security and privacy. We conduct a literature review for each category of RFID limitations, and provide the solutions outlined in the literature for each limitation.

\subsubsection{Organizational Limitations}

Scholars have cited the organizational challenges that limit RFID adoption in agricultural cold chain monitoring, 
which include a lack of skilled personnel (Asif, 2005; Attaran, 2009; Raab et al., 2011; Ruiz-Garcia \& Lunadei, 2011), resistance to change, a lack of top management support, a lack of system integration (Attaran, 2009), and poor consumer adoption (Estrada-Flores \& Tanner, 2008). Estrada-Flores and Tanner (2008) suggested that RFID-enabled refrigerators with functions such as sending a shopping list to the owner's cell phone could make the benefits of RFID more evident for consumers and thus improve consumer adoption of the RFID system.

\subsubsection{Technical Limitations}

Besides organizational challenges, the technological limitations of RFID adoption have been mentioned in the literature. Some of these are related to the structure of the RFID system. Each component of the RFID system is subject to several limitations; we categorize these based on the challenges related to each component.

Previous RFID applications in agricultural cold chain monitoring have revealed some limitations related to RFID tags. First of all, multiple types of RFID sensors (e.g., semi-passive temperature sensors and passive tags) need different architectures, as they require different environments for identification (Delen et al., 2011). Sensing diversity has also been cited as a limitation of RFID application; i.e., usually, RFID technology will be limited by a single sensor, such as temperature (Aung \& Chang, 2014; Badia-Melis et al., 2018). In addition, RFID tags are not able to initiate communication (Aung \& Chang, 2014). Tagging level can also affect the efficiency of cold chain monitoring. RFID tagging can be implemented at the pallet level, case level, and item level. Pallet-level tagging is a remarkable challenge when different products are transported together, since different products show different sensitivity to temperature (Raab et al., 2011). Aung and Chang (2014) looked to identify the optimal temperature setting for an environment including chilled and chill-sensitive with different temperatures. For this purpose, they proposed a smart cold chain management (SCCM) framework, in which an RFID tag is attached to the stock keeping unit (SKU) of each product and a WSN system is deployed to each cold chain facility. On the other hand, Ruiz-Garcia and Lunadei (2010) pointed out the advantage of item-level tagging in providing more detailed information, as even within the same pallet or case, different items can experience different temperatures (depending on their distance from the cooling unit or from the walls, etc.) and non-uniform ripening. Thus, item-level tagging could be beneficial in preventing errors in decision-making that has been based on temperatures affecting only part of the load (Grunow \& Piramuthu, 2013).

Tag cost is a major restrictive factor in the implementation of RFID technology in the agri-food industry (Table 2). Ruiz-Garcia and Lunadei (2011) pointed out that the average cost of RFID tagging is considered overly expensive for low-value agricultural products such as fruits and vegetables (Regattieri et al., 2007; Chunxia et al., 2009; Ruiz-Garcia \& Lunadei, 2011). Several researchers have provided solutions for coping with this limitation. Bhattacharyya et al. (2010) discussed the potential for RFID tags to be used as low-cost sensors in monitoring the cold chain for agricultural products. According to the authors, this could be done through plotting a change in a physical parameter of interest to a controlled change in the electrical properties of the RFID tag antenna. Some authors, such as Jedermann and Lang (2007), Amador and Edmond (2010), and Trebar et al. (2013), have suggested reducing the number of tags. In their study, Jedermann and Lang (2007) reduced the number of tags in the Intelligent Container, while Amador and Edmond (2010) suggested reducing the number of tags by installing them in a location where the temperature is the middle point of an interval. Trebar et al. (2013) suggested reusable smart tags, called RFID-TLs. In another study, Chen et al. (2014) proposed the application of a new type of RFID named 2G-RFID-Sys (second-generation RFID systems). In the 2G-RFID-Sys, a dynamic rule encoding "mobile code" is stored in the tag. One of the main advantages of this system is that it replaces semi-passive tags with passive tags, hence reducing the cost. Zou et al. (2014) suggested on-tag algorithm processing or multiple environmental sensors and a combination of passive, semi-passive, and active RFID. Sima et al. (2017) developed a flexible RFID smart tag for temperature monitoring as a cost-effective solution. Finally, Badia-Melis et al. (2018) stated that this problem could be solved by reducing the number of sensors deployed.

Several challenges concerning the RFID reader were also found in the literature; among these was the readability of RFID tags. Some authors mentioned the low reading range of RFID tags as a disadvantage of the technology (Table 2). According to Kumar et al. (2009), most low-frequency RFID systems have an operating range of about 1 meter, and ultra-high frequency systems extend the operating range to 3 to 4 meters. However, Badia-Melis et al. (2015) demonstrated that a combination of a WSN and RFID could solve the problem of the tags' low reading range, as a WSN offers a long reading range. The RFID tags' reading range can be affected by different factors. Gras (2006) stated, "Material mounted transponders could lead to different reading ranges." Another critical issue is the sensitivity of RFID tags' readability to environmental factors such as dust, moisture, extreme temperatures, the presence of metallic objects, and the high water content of tagged materials (Table 2). Using RFID tags for agri-food products that have a high water content and are usually transported in metal containers, such as fruits and vegetables, could be challenging (Angeles, 2005; Ruiz-Garcia, 2008). This limitation results in 
the generation of inaccurate spoilage predictions and increased food spoilage (Bedia melis et al., 2018). To cope with this challenge, Laniel et al. (2011) suggested the use of non-metallic containers for transporting perishables by air. Li et al. (2012) suggested the link quality indicator be measured in a cargo container filled with watered Styrofoam boxes (Note 2) to ensure excellent reading efficiency of the WSN. Several authors tested the RFID antenna position to achieve full RFID tag readability and strove to find a frequency/configuration that would allow real-time reading of the temperature in a shipment of perishable products using RFID. Laniel et al. (2009) concluded a significantly higher performance at the $433 \mathrm{MHz}$ level (compared to $915 \mathrm{MHz}$ and $2.45 \mathrm{GHz}$ ). Moreover, an RFID antenna positioned at the front of a container of perishable products delivered slightly better results than the one in the middle of the ceiling. Laniel and Émond (2010) concluded that canned vegetables provide the best RFID tag reading, followed by fresh meat and frozen bread. The results of their study demonstrated that radio waves at $915 \mathrm{MGH}$ are absorbed by high water and ice contents. However, spacing between metal surfaces and tags can allow excellent RFID readability even if the radio frequency reflects on metallic surfaces. The authors suggested that RFID tags placed on the top of a pallet have a higher chance of producing a successful read. The results of a study by Laniel et al. (2011) showed that antenna position affects RFID readability at $915 \mathrm{MHz}$, while $433 \mathrm{MHz}$ demonstrated $100 \%$ readability in all antenna positions. Trebar et al. (2013) concluded that a high frequency is considered the best solution for the integration of foods with water conditions.

Accuracy is also a concern with the RFID reader. Significant factors affecting the reader's accuracy are the visibility of tags to the reader (Asif, 2005; Kumar et al., 2009) and harsh conditions in the cold chain. Although in harsh conditions RFID tags might continue to work, readers fail to register tagged pallets (Estrada-Floes \& Tanner, 2008; Aung \& Chang, 2014). It is worth mentioning that the probe-less RFID system fails to provide an accurate temperature reading in critical corners of a pallet (Amador et al., 2009). Amador et al. (2009) proposed the use of RFID semi-passive tags with a probe for tracking low temperature abuse in the transportation and refrigerated storage of products.

Data management can be considered a limitation of RFID information management software. As mentioned earlier, RFID enables continuous temperature data collection. Although this characteristic is very beneficial in cold chain monitoring, managing the huge amount of data produced by RFID data loggers is a restrictive factor in its adoption (Table 2). Moreover, a large volume of data leads to high hardware cost (Jedermann et al., 2009). However, Badia-Melis et al. (2015) and Badia-Melis et al. (2016) stated that in the case of creating a uniform mesh of temperature nodes with many data points, which is necessary for 3D representation, a large volume of data is not a limitation. Fortunately, several suggestions to combat this limitation were found in the literature. Referring to the patent of Martin and Grabiner (2007), who proposed the integration of RFID tags with a visually readable environmental condition exposure indicator, Jedermann and Lang (2007) and Jedermann et al. (2008) suggested replacing huge amounts of temperature data with a temperature threshold checker and a quality indicator, respectively. In another study, Jedermann et al. (2009) stated that the solution to this limitation lies in implementing a decentralized data management system in which temperature data are pre-processed close to their point of origin by intelligent systems. Finally, Raab et al. (2011) proposed that temperature monitoring system providers consider reducing large amounts of data into a summarized form to enable rapid management decision-making.

Real-time data transfer to the RFID interface is considered another challenge of RFID database and information management software. Several authors argued that previous methods of temperature monitoring using RFID tags with integrated temperature sensors (Jedermman \& Lang, 2007; Thakur et al., 2011) could not retrieve information in real time when the product was in transit (Note 3) (Thakur \& Foras, 2015). Integrating RFID with other technologies, these authors improved ancient methods of temperature monitoring to achieve a real-time monitoring system (Zhang et al., 2009; Wang et al., 2010; Thakur \& Foras, 2015).

Other technical challenges besides those related to the structure of the RFID system were found in the literature. A lack of both uniform standards and a non-uniform calibration procedure between manufactures and models remain challenges of RFID implementation in cold chain monitoring (Table 2). Although EPCglobal and the International Standards Organization (ISO) worked to develop international standards for RFID technologies in the UHF (ultra-high frequency) spectrum, the standards put forth by these organizations were not completely compatible with each other (Chunxia et al., 2009). McMeekin et al. (2006) proposed using the EAN.UCC system to solve the problem of non-uniform standards.

Jedermann et al. (2006) pointed out the lack of a suitable quality indicator as a technical challenge of RFID application in cold chain monitoring. Since commonly used quality indicators-including firmness, starch and sugar content, taste, and color - are not suitable for automated supervision because the products have to be 
unpacked and handled manually, the authors looked to improve these indicators by combining a WSN and RFID. By incorporating a factor directly associated with the internal metabolic process, their quality indicator measures the quality of the fruit itself.

RFID also has high energy consumption, which can be solved using an ultra-low power complementary metal oxide semiconductor (CMOS) with room-temperature targeting (Law et al., 2010).

The high cost of RFID implementation and small value added of agricultural products have led researchers to challenge the economic benefits of RFID technology in the food industry (Table 2). An RFID system must be customized to its specific working environment and application process (Chunxia et al., 2009), which is costly. Given the high cost of RFID application, Chunxia et al. (2009) considered return on investment an important issue in RFID application in the vegetable supply chain with low value added. Delen et al. (2011) justified the return on investment in their application by an increase in quality, which would promote sales, and the reduced risk of losing a customer due to poor-quality products.

\subsubsection{Limitations Related to Security and Privacy}

Security and privacy concerns represent a significant limitation of RFID implementation (Table 2). Consumers are concerned about automatic tracking of their movements and buying habits. An unauthorized user of an RFID system can also scan tags to access private information such as shipment and inventory details (Kumar et al., 2009). Langheinrich (2009) stated that because of the tags' low computational powers, a simple system must be configured to prevent tampering with data and to protect privacy.

Table 2. Challenges of RFID application in cold chain monitoring of agricultural products and suggested solutions

\begin{tabular}{|c|c|c|}
\hline Author & Challenge & Solution \\
\hline \multicolumn{3}{|l|}{ Organizational Challenges } \\
\hline Estrada-Flores \& Tanner, 2008 & - Consumer adoption & $\begin{array}{l}\text { - Estrada-Flores and Tanner (2008) suggested RFID-enabled } \\
\text { domestic refrigerators with functions such as sending a shopping } \\
\text { list to the owner's cellphone }\end{array}$ \\
\hline $\begin{array}{l}\text { Asif, 2005; Attaran, 2009; Raab et al., 2011; } \\
\text { Ruiz-Garcia \& Lunadei, } 2011\end{array}$ & - Lack of skilled personnel & \\
\hline Attaran, 2009 & $\begin{array}{l}\text { - Resistance to change } \\
\text { - } \quad \text { Lack of top management } \\
\text { support } \\
\text { - } \quad \text { Lack of system integration }\end{array}$ & \\
\hline \multicolumn{3}{|l|}{ Technical Challenges } \\
\hline \multicolumn{3}{|l|}{ Limitations Related to RFID Tags } \\
\hline Delen et el., 2011 & $\begin{array}{l}\text { - Environment requirement of } \\
\text { multiple types of sensors }\end{array}$ & \\
\hline $\begin{array}{l}\text { Raab et al., 2011; Grunow \& Piramuthu, 2013; } \\
\text { Aung an Chang, } 2014\end{array}$ & - Pallet-level tagging & $\begin{array}{l}\text { - Ruiz-Garcia and Lunadei (2010) proposed item-level tagging } \\
\text { - Grunow and Piramuthu (2013) proposed the application of } \\
\text { item-level RFID tags } \\
\text { - Aung and Chang (2014) decided the optimal target temperature in } \\
\text { a multi-commodity cold storage management }\end{array}$ \\
\hline Aung \& Chang, 2014 & $\begin{array}{l}\text { - Disability of a tag to initiate } \\
\text { communication }\end{array}$ & \\
\hline $\begin{array}{l}\text { Aung \& Chang, 2014; Badia-Melis et al., } 2018 \\
\text { Asif, 2005; Michael \& McCathie, 2005; } \\
\text { Narsing, 2005; Jedermann \& Lang, 2007; } \\
\text { Regattieri et al., 2007; Erdem et al., 2008; } \\
\text { Estrada-Flores \& Tanner, 2008; Abad et al., } \\
\text { 2009; Chunxia et al., 2009; Amador \& } \\
\text { Edmond, 2010; Bhattacharyya et al., 2010; Zou } \\
\text { et al., 2014; Aung \& Chang, 2014; Sima et al., } \\
\text { 2017; Badia-Melis et al., } 2018\end{array}$ & $\begin{array}{l}\text { - Lack of sensing diversity } \\
\text { - High cost of tags }\end{array}$ & $\begin{array}{l}\text { - Jedermann and Lang (2007) suggested intelligent or smart } \\
\text { container } \\
\text { - Amador \& Edmond (2010) suggested tag installation at a location } \\
\text { with a temperature at the middle point of an interval } \\
\text { - Bhattacharyya et al. (2010) suggested a low-cost RFID tag by } \\
\text { mapping a change in some physical parameter of interest to a } \\
\text { controlled change in RFID tag antenna electrical properties } \\
\text { - Trebar et al. (2013) suggested RFID-TLs (reusable smart tags) } \\
\text { - Chen et al. (2014) proposed a smart cold chain system } \\
\text { - Zou et al. (2014) suggested on-tag algorithm processing or } \\
\text { multiple environmental sensors } \\
\text { - Sima et al. (2017) developed a flexible RFID smart tag for } \\
\text { temperature monitoring } \\
\text { - Badia-Melis et al. (2018) stated that cost reduction is possible by } \\
\text { reducing the number of sensors deployed }\end{array}$ \\
\hline
\end{tabular}


Limitations Related to RFID Readers Gras (2006)

Asif, 2005; Estrada-Flores \& Tanner, 2008; Kumar et al., 2009; Aung \& Chang, 2014 Amador et al. (2009)

Kumar et al., 2009; Ruiz-Garcia et al., 2009; Ruiz-Garcia \& Lunadei, 2010;

Angeles, 2005, Asif, 2005; Dobkin \& Weig\&, 2005; Narsing, 2005; Regattieri et al., 2007; Ruiz-Garcia, 2008; Laniel et al., 2009; Laniel \& Émond, 2010; Amador \& Edmond, 2010; Ruiz-Garcia \& Lunadei, 2010; Laniel et al., 2011; Raab et al., 2011; Li et al., 2012; Trebar et al., 2013; Aung \& Chang, 2014; Kumari et al., 2015; Badia-Melis et al., 2018

- Material-mounted transponders could lead to different reading ranges

- Reader accuracy

- Failure of probe-less RFID system to provide accurate temperature readings in some critical points of the pallet

- Low reading range

- Badia-Melis et al. (2018) combined RFID and a WSN

Sensitivity of tag readability to environmental conditions

- Laniel et al. (2009) found a relationship between antenna position and RFID readability:

$>$ They found that the antenna positioned at the front of the container demonstrates better readability than one in the middle of the ceiling

$>$ Moreover, they found a frequency and configuration (433 $\mathrm{MHz}$ ) that would allow real-time reading of the temperature in shipments of perishable products using RFID

- Laniel and Émond (2010) found:

$>$ RFID tags placed on top of a pallet have a higher chance of producing a successful read

$>$ Spacing between metal surfaces and tags can allow excellent RFID readability even if the radio frequency reflects off metallic surfaces

- Laniel et al. (2011) concluded:

$>$ The antenna position affects RFID readability at $915 \mathrm{MHz}$

> A 433 MHz-RFID system appears suitable for real-time temperature monitoring of frozen bread

- Laniel et al. (2011) suggested the use of non-metallic containers

- Li et al. (2012) proposed a wireless sensor module

- According to Trebar et al. (2013), a high frequency is considered the best solution for the integration of foods with water conditions

Limitations Related to Database and Information Management Software

Jedermann \& Lang, 2007; Martin \& Grabiner, • Data management

2007; Erdem et al., 2008; Estrada-Flores \&

- Data management

Tanner, 2008; Jedermann et al., 2008;

Jedermann et al., 2009; Ruiz-Garcia \& Lunadei,

2010; Raab et al., 2011; Ruiz-Garcia \&

Lunadei, 2011; Kumari et al., 2015

Thakur \& Foras, 2015

- Lack of the ability to retrieve information in real time when the product is in transit
- Jedermann and Lang (2007) suggested to equip RFID data loggers with additional preprocessing facilities

- Jedermann et al. (2008) suggested intelligent RFID

- Jedermann et al. (2009) implemented a decentralized data management system

- Raab et al. (2011) suggested that temperature monitoring system providers think about reducing the huge amount of data into a summarized form to enable quick management decisions

- Zhang et al. (2009) developed a temperature-managed traceability system combining RFID tag, GPS, and mobile communication

- Wang et al. (2010) used RFID combined with an online decision support system

- Thakur and Foras (2015) proposed an Electronic Product Code Information Service (EPCIS)-based online system

\section{Other Technical Limitations}

Jedermann et al. (2006)

Law et al. (2010)

Asif, 2005; Michael \& McCathie, 2005;

Narsing, 2005; Regattieri et al., 2007

Estrada-Flores \& Tanner, 2008; Abad et al.,

2009; Chunxia et al., 2009; Yan \& Lee, 2009;

Ruiz-Garcia \& Lunadei, 2010; Delen et el.,

2011; Raab et al., 2011
- Lack of a compatible quality indicator

- High voltage consumption

- Lack of uniform standards
- Jedermann et al. (2006) derived a quality index that measures the quality of the produce itself

- Law et al. (2010) proposed an ultra-low-power CMOS temperature sensor

- McMeekin et al. (2006) suggested the implementation of an EAN.UCC system 


\begin{tabular}{|c|c|c|}
\hline $\begin{array}{l}\text { Chunxia et al., 2009; Yan \& Lee, 2009; Delen } \\
\text { et al., 2011; Raab et al., 2011; Ruiz-Garcia \& } \\
\text { Lunadei, 2011; Kumari et al., 2015; Thakur \& } \\
\text { Foras., } 2015\end{array}$ & - High cost of implementation & $\begin{array}{l}\text { Delen et al. (2011) justified the return on investment in their } \\
\text { application by a reduction in spoiled products, an increase in } \\
\text { quality that would promote sales, and the reduced risk of losing a } \\
\text { customer due to poor quality products }\end{array}$ \\
\hline \multicolumn{3}{|l|}{ Challenges Related to Security and Privacy } \\
\hline $\begin{array}{l}\text { Asif, 2005; Michael \& McCathie, 2005; Kumar } \\
\text { \& Budin, 2006; Kumar et al., 2009; } \\
\text { Langheinrich, 2009; Yan \& Lee, 2009; } \\
\text { Ruiz-Garcia \& Lunadei, } 2010\end{array}$ & - Security and privacy & $\begin{array}{l}\text { - Langheinrich (2009) stated that with the low computational } \\
\text { powers available within the tags, a system to prevent tampering } \\
\text { with data to protect privacy must be simple }\end{array}$ \\
\hline
\end{tabular}

\section{Discussion and Conclusion}

From 2004 to 2018, the application of RFID technology in agriculture increased rapidly. Although RFID brings new features to traditional temperature monitoring when adopted in cold chain monitoring, some challenges limit the technology's application.

The main reasons for the enthusiasm for RFID adoption in cold chain monitoring are its ability to integrate temperature sensors, provide real-time information, and work in the harsh conditions of cold chains. Table 1 presents the advantages of RFID application in monitoring the cold chain for agricultural products cited by scholars during 2004-2018. These advantages are categorized into: time saving, data collection, risk management, structure (of the RFID system) and economic benefits. The significant advantages of RFID application in temperature monitoring have led researchers to look for solutions to the limitations of the application of this technology in the cold chain of perishables. We categorized the challenges of RFID implementation in cold chain monitoring according to Nambiar (2009) into organizational, technical, and those related to security and privacy; technical challenges were further categorized into limitations related to RFID tags, readers, database and information management software, and others (Table 2). The solutions offered in the literature for these limitations are presented in Table 2. Given the long period (14 years) that RFID has now been adopted in cold chain monitoring, organizational limitations such as a lack of skilled personnel are no longer an issue, nor is a lack of management support, as the risks associated with new technology adoption occurs in the first stages of its emergence, and the significant benefits offered by RFID earn management support for its adoption and provides sufficient incentive to the manager to train personnel. Technical challenges were the most cited concerns with RFID implementation in cold chain monitoring during 2004-2018 (Table 2); while solutions were found for some of these, some technical challenges (environmental requirements of multiple types of sensors, sensing diversity, tags' failure to initiate communication, and reader accuracy) remain. Reader accuracy is a serious challenge, since it can be affected by the harsh conditions of the cold chain, leading to error in decision-making. Finally, the unauthorized traceability of buyers and venders remains an issue.

This literature review outlines the evolution of RFID application in agricultural products cold chain monitoring. Several solutions have been found over time for fundamental issues arising from RFID application in temperature monitoring. Thus, given the technology's significant advantages, it could be considered a viable method of temperature control providing both direct and indirect benefits to the involved parties. The application of RFID technology is becoming more and more beneficial, as tag cost has been steadily declining recently and has reached the threshold value, making RFID application profitable (RFID journal, 2018). Moreover, as RFID infrastructure is now built across the entire food supply chain (cultivating, processing, storage, transportation, and retailing), the resulting economies of scale leads to more benefits overall for the agricultural industry.

\section{References}

Abad, E., Palacio, F., Nuin, M., De Zarate, A. G., Juarros, A., Gómez, J. M., \& Marco, S. (2009). RFID smart tag for traceability and cold chain monitoring of foods: Demonstration in an intercontinental fresh fish logistic chain. Journal of Food Engineering, 93(4), 394-399. https://doi.org/10.1016/j.jfoodeng.2009.02.004

Aitken, J. (1998). Supply Chain Integration within the Context of a Supplier Association (PHD Thesis, Cranfield University). Cited in Christopher, M. (1998). Logistics and Supply Chain Management. Strategies for Reducing Cost and Improving Service. Financial Times Pitman Publishing, London.

Amador, C., \& Emond, J. P. (2010). Evaluation of sensor readability and thermal relevance for RFID temperature tracking. Computers and Electronics in Agriculture, 73(1), 84-90. https://doi.org/10.1016/ j.compag.2010.04.006 
Amador, C., Emond, J. P., \& do Nascimento Nunes, M. C. (2009). Application of RFID technologies in the temperature mapping of the pineapple supply chain. Sensing and Instrumentation for Food Quality and Safety, 3(1), 26-33. https://doi.org/10.1007/s11694-009-9072-6

Angeles, R. (2005). RFID technologies: Supply-chain applications and implementation issues. Information Systems Management, 22(1), 51e65. https://doi.org/10.1201/1078/44912.22.1.20051201/85739.7

Asif, Z. (2005). Integrating the supply chain with RFID: A technical and business analysis. Communications of the Association for Information Systems, 15(1), 24. https://doi.org/10.17705/1CAIS.01524

Attaran, M. (2007). RFID: An enabler of supply chain operations. Supply Chain Management-an International Journal, 12(4), 249e257. https://doi.org/10.1108/13598540710759763

Attaran, M. (2009). Keeping the promise of efficiency: RFID's trends and its renewed popularity. Industrial Engineer, 41(3), 45-50.

Aung, M. M., \& Chang, Y. S. (2014). Temperature management for the quality assurance of a perishable food supply chain. Food Control, 40, 198-207. https://doi.org/10.1016/j.foodcont.2013.11.016

Aung, M. M., \& Chang, Y. S. (2014). Traceability in a food supply chain: Safety and quality perspectives. Food Control, 39, 172-184. https://doi.org/10.1016/j.foodcont.2013.11.007

Badia-Melis, R., Mc Carthy, U., \& Uysal, I. (2016). Data estimation methods for predicting temperatures of fruit in refrigerated containers. Biosystems Engineering, 151, 261-272. https://doi.org/10.1016/j.biosystemseng. 2016.09.009

Badia-Melis, R., Mc Carthy, U., Ruiz-Garcia, L., Garcia-Hierro, J., \& Villalba, J. R. (2018). New trends in cold chain monitoring applications: A review. Food Control, 86, 170-182. https://doi.org/10.1016/j.foodcont. 2017.11.022

Badia-Melis, R., Ruiz-Garcia, L., Garcia-Hierro, J., \& Villalba, J. I. R. (2015). Refrigerated fruit storage monitoring combining two different wireless sensing technologies: RFID and WSN. Sensors, 15(3), 4781-4795. https://doi.org/10.3390/s150304781

Bhattacharyya, R., Floerkemeier, C., \& Sarma, S. (2010). Low-cost, ubiquitous RFID-tag-antenna-based sensing. Proceedings of the IEEE, 98(9), 1593-1600. https://doi.org/10.1109/JPROC.2010.2051790

Buchner, B., Fischler, C., Gustafson, E., Reilly, J., Riccardi, G., Ricordi, C., \& Veronesi, U. (2012). Food waste: Causes, impacts and proposals. Barilla Center for Food and Nutrition. Retrieved from https://www. barillacfn. com/media/publications/food-waste-causes-impactproposals.pdf

Chappell, G., Durdan, D., Gilbert, G., Ginsburg, L., Smith, J., \& Tobolski, J. (2003). Auto-ID in the box: The value of Auto-ID technology in retail stores. Auto-ID Center, 2(2).

Chen, K. Y., \& Shaw, Y. C. (2011). Applying back propagation network to cold chain temperature monitoring. Advanced Engineering Informatics, 25(1), 11-22. https://doi.org/10.1016/j.aei.2010.05.003

Chen, Y. Y., Wang, Y. J., \& Jan, J. K. (2014). A novel deployment of smart cold chain system using 2G-RFID-Sys. Journal of Food Engineering, 141, 113-121. https://doi.org/10.1016/j.jfoodeng.2014.05.014

Chunxia, W., Weimin, Y., Yingyan, P., \& Huiyuan, X. (2009). Research on RFID technology adoption of vegetable supply chain in China (Vol. 2, pp. 669-672). International Forum Information Technology and Applications, 2009, IEEE. https://doi.org/10.1109/IFITA.2009.200

Delen, D., Sharda, R., \& Hardgrave, B. C. (2011). The promise of RFID-based sensors in the perishables supply chain. IEEE Wireless Communications, 18(2). https://doi.org/10.1109/MWC.2011.5751300

Dobkin, D. M., \& Weigand, S. M. (2005). Environmental effects on RFID tag antennas (Vol. 2005, pp. 135-138). IEEE MTT-S International Microwave Symposium Digest. https://doi.org/10.1109/MWSYM.2005.1516541

Erdem, E., Zeng, H., Shi, J., \& Wells, D. L. (2008). Application of RFID and sensing technology for improving frozen food quality management. RFID in operations and supply chain management: Research and application (pp. 221-245). Erich Schmidt Verlag GmbH \& Co., Berlin.

Estrada-Flores, S., \& Tanner, D. (2008). RFID technologies for cold chain applications. Bulletin of the International Institute of Refrigeration (IIR), (2004-8), 4-8.

Foley, C. (2006). Radio frequency identification (RFID) tags copper content detrimental to recycling. Retrieved from http://www.recyclingtech.org 
Gras, D. (2006, May). RFID based monitoring of the cold chain. Proc. 2nd international Workshop Cold Chain Managemen (pp. 81-82). Bonn, Germany.

Grunow, M., \& Piramuthu, S. (2013). RFID in highly perishable food supply chains-remaining shelf life to supplant expiry date? International Journal of Production Economics, 146(2), 717-727. https://doi.org/ 10.1016/j.ijpe.2013.08.028

Gustavsson, J., Cederberg, C., Sonesson, U., Van Otterdijk, R., \& Meybeck, A. (2011). Global food losses and food waste (pp. 1-38). Rome: FAO.

Heising, J. K., Dekker, M., Bartels, P. V., \& Van Boekel, M. A. J. S. (2014). Monitoring the quality of perishable foods: opportunities for intelligent packaging. Critical Reviews in Food Science and Nutrition, 54(5), 645-654. https://doi.org/10.1080/10408398.2011.600477

Hertog, M. L. A. T. M., Yudhakusuma, R. F., Snoekx, P., De Baerdemaeker, J., \& Nicolaï, B. M. (2006). Smart traceability systems to satisfy consumer expectations (pp. 407-415). XXVII International Horticultural Congress-IHC2006: International Symposium on the Role of Postharvest Technology in the 768.

Hong, I. H., Dang, J. F., Tsai, Y. H., Liu, C. S., Lee, W. T., Wang, M. L., \& Chen, P. C. (2011). An RFID application in the food supply chain: A case study of convenience stores in Taiwan. Journal of Food Engineering, 106(2), 119-126. https://doi.org/10.1016/j.jfoodeng.2011.04.014

Jedermann, R., \& Lang, W. (2007). Semi-passive RFID and beyond: steps towards automated quality tracing in the food chain. International Journal of Radio Frequency Identification Technology and Applications, 1(3), 247-259. https://doi.org/10.1504/IJRFITA.2007.015849

Jedermann, R., Behrens, C., Westphal, D., \& Lang, W. (2006). Applying autonomous sensor systems in logistics-Combining sensor networks, RFIDs and software agents. Sensors and Actuators A: Physical, 132(1), 370-375. https://doi.org/10.1016/j.sna.2006.02.008

Jedermann, R., Emond, J. P., \& Lang, W. (2008). Shelf life prediction by intelligent RfiD-Technical limits of model accuracy. Dynamics in Logistics (pp. 231-238). Springer, Berlin, Heidelberg. https://doi.org/ 10.1007/978-3-540-76862-3 22

Jedermann, R., Ruiz-Garcia, L., \& Lang, W. (2009). Spatial temperature profiling by semi-passive RFID loggers for perishable food transportation. Computers and Electronics in Agriculture, 65(2), 145-154. https://doi.org/ 10.1016/j.compag.2008.08.006

Jones, P., Clarke-Hill, C., Shears, P., Comfort, D., \& Hillier, D. (2004). Radio frequency identification in the UK: Opportunities and challenges. International Journal of Retail and Distribution Management, 32(3), $164 \mathrm{e} 17$. https://doi.org/10.1108/09590550410524957

Kang, Y. S., Jin, H., Ryou, O., \& Lee, Y. H. (2012). A simulation approach for optimal design of RFID sensor tag-based cold chain systems. Journal of Food Engineering, 113(1), 1-10. https://doi.org/10.1016/j.jfoodeng. 2012.05.036

Kärkkäinen, M. (2003). Increasing efficiency in the supply chain for short shelf life goods using RFID tagging. International Journal of Retail \& Distribution Management, 31(10), 529-536. https://doi.org/10.1108/0959 0550310497058

Kärkkäinen, M. (2005). Forwarder independent tracking systems: Problem description and solution design proposal.

Ketzenberg, M., Bloemhof, J., \& Gaukler, G. (2015). Managing perishables with time and temperature history. Production and Operations Management, 24(1), 54-70. https://doi.org/10.1111/poms.12209

Kim, K., Kim, H., Kim, S. K., \& Jung, J. Y. (2016). i-RM: An intelligent risk management framework for context-aware ubiquitous cold chain logistics. Expert Systems with Applications, 46, 463-473. https://doi.or g/10.1016/j.eswa.2015.11.005

Kumar, P., Reinitz, H. W., Simunovic, J., Sandeep, K. P., \& Franzon, P. D. (2009). Overview of RFID technology and its applications in the food industry. Journal of Food Science, 74(8). https://doi.org/10.1111/ j.1750-3841.2009.01323.x

Kumar, S., \& Budin, E. M. (2006). Prevention and management of product recalls in the processed food industry: A case study based on an exporter's perspective. Technovation, 26(5-6), 739-750. https://doi.org/10.1016/ j.technovation.2005.05.006 
Kumari, L., Narsaiah, K., Grewal, M. K., \& Anurag, R. K. (2015). Application of RFID in agri-food sector. Trends in Food Science \& Technology, 43(2), 144-161. https://doi.org/10.1016/j.tifs.2015.02.005

Langheinrich, M. (2009). A survey of RFID privacy approaches. Personal and Ubiquitous Computing, 13(6), 413-421. https://doi.org/10.1007/s00779-008-0213-4

Laniel, M. A. G. A. L. I. E., Uysal, I. S. M. A. I. L., \& Emond, J. P. (2011). Radio frequency interactions with air cargo container materials for real-time cold chain monitoring. Applied Engineering in Agriculture, 27(4), 647-652. https://doi.org/10.13031/2013.38195

Laniel, M., \& Émond, J. P. (2010). Mapping of RFID tag readability in relation to the food content in a refrigerated sea container at 915 MHz. Innovative Food Science \& Emerging Technologies, 11(4), 703-706. https://doi.org/10.1016/j.ifset.2010.06.005

Laniel, M., Emond, J. P., \& Altunbas, A. E. (2009). RFID behavior study in enclosed marine container for real time temperature tracking. Sensing and Instrumentation for Food Quality and Safety, 3(1), 34-40. https://doi.org/10.1007/s11694-009-9075-3

Laniel, M., Émond, J. P., \& Altunbas, A. E. (2011). Effects of antenna position on readability of RFID tags in a refrigerated sea container of frozen bread at 433 and $915 \mathrm{MHz}$. Transportation Research Part C: Emerging Technologies, 19(6), 1071-1077. https://doi.org/10.1016/j.trc.2011.06.008

Law, M. K., Bermak, A., \& Luong, H. C. (2010). A Sub-\$mu \$ W Embedded CMOS Temperature Sensor for RFID Food Monitoring Application. IEEE Journal of Solid-State Circuits, 45(6), 1246-1255. https://doi.org/ 10.1109/JSSC.2010.2047456

Li, C. M., Nien, C. C., Liao, J. L., \& Tseng, Y. C. (2012). Development of wireless sensor module and network for temperature monitoring in cold chain logistics (pp. 1-4). 2012 IEEE International Conference Wireless Information Technology and Systems (ICWITS), IEEE. https://doi.org/10.1109/ICWITS.2012.6417745

Li, D., Kehoe, D., \& Drake, P. (2006). Dynamic planning with a wireless product identification technology in food supply chains. The International Journal of Advanced Manufacturing Technology, 30(9-10), 938-944. https://doi.org/10.1007/s00170-005-0066-1

Li, S., Visich, J. K., Khumawala, B. M., \& Zhang, C. (2006). Radio frequency identification technology: Applications, technical challenges and strategies. Sensor Review, 26(3), 193-202. https://doi.org/10.1108/ 02602280610675474

Lorite, G. S., Selkälä, T., Sipola, T., Palenzuela, J., Jubete, E., Viñuales, A., ... Hakalahti, L. (2017). Novel, smart and RFID assisted critical temperature indicator for supply chain monitoring. Journal of Food Engineering, 193, 20-28. https://doi.org/10.1016/j.jfoodeng.2016.06.016

Luo, Q., Xiong, B., Geng, Z., Yang, L., \& Pan, J. (2010). A study on pig slaughter traceability solution based on RFID (pp. 710-720). International Conference on Computer and Computing Technologies in Agriculture. Springer, Berlin, Heidelberg.

Martin, J. P., \& Grabiner, F. R. (2007). U.S. Patent No. 7,209,042. Washington, DC: U.S. Patent and Trademark Office.

McMeekin, T. A., Baranyi, J., Bowman, J., Dalgaard, P., Kirk, M., Ross, T., ... \& Zwietering, M. H. (2006). Information systems in food safety management. International Journal of Food Microbiology, 112(3), 181-194. https://doi.org/10.1016/j.ijfoodmicro.2006.04.048

Michael, K., \& McCathie, L. (2005). The pros and cons of RFID in supply chain management (pp. 623-629). International Conference on Mobile Business, 2005, IEEE. https://doi.org/10.1109/ICMB.2005.103

Montanari, R. (2008). Cold chain tracking: A managerial perspective. Trends in Food Science \& Technology, 19(8), 425-431. https://doi.org/10.1016/j.tifs.2008.03.009

Nambiar, A. N. (2009). RFID technology: A review of its applications. Proceedings of the World Congress on Engineering and Computer Science (Vol. 2, pp. 20-22).

Narsing, A. (2005). RFID and supply chain management: an assessment of its economic, technical, and productive viability in global operations. Journal of Applied Business Research, 21(2), 75-80

Ngai, E., \& Riggins, F. (2008). RFID: Technology, applications, and impact on business operations. International Journal of Production Economics, 112(2), 507e509. https://doi.org/10.1016/j.ijpe.2007.05.003 
Ogasawara, A., \& Yamasaki, K. (2006). A temperature-managed traceability system using RFID tags with embedded temperature sensors. NEC Technical Journal, 1(2), 82-86.

Opara, L. U. (2003). Traceability in agriculture and food supply chain: A review of basic concepts, technological implications, and future prospects. Journal of Food Agriculture and Environment, 1, 101-106.

Pang, Z., Chen, Q., \& Zheng, L. (2011). Scenario-based design of wireless sensor system for food chain visibility and safety. Advances in Computer, Communication, Control and Automation (pp. 541-548). Springer, Berlin, Heidelberg. https://doi.org/10.1007/978-3-642-25541-0_69

Pope, G., Myers, T. E., Kaye, S., \& Burchell, J. (2009). U.S. Patent No. 7,495,558. Washington, DC: U.S. Patent and Trademark Office.

Raab, V., Petersen, B., \& Kreyenschmidt, J. (2011). Temperature monitoring in meat supply chains. British Food Journal, 113(10), 1267-1289. https://doi.org/10.1108/00070701111177683

Raza, N., Bradshaw, V., \& Hague, M. (1999). Applications of RFID technology.

Regattieri, A., Gamberi, M., \& Manzini, R. (2007). Traceability of food products: General framework and experimental evidence. Journal of Food Engineering, 81(2), 347-356. https://doi.org/10.1016/j.jfoodeng. 2006.10.032

RFID Frequently Asked Question. (2018). RFID Journal. Retrieved November 1, 2018, from https://www. rfidjournal.com/faq/show?85

Ruiz-García, L. (2008). Development of monitoring applications for refrigerated perishable goods transportation (Doctoral dissertation, Agronomos).

Ruiz-Garcia, L., \& Lunadei, L. (2010). Monitoring cold chain logistics by means of RFID. Sustainable radio frequency identification solutions. Cited in Samad, A., Murdeshwar, P., \& Hameed, Z. (2010). High-credibility RFID-based animal data recording system suitable for smallholding rural dairy farmers. Computers and Electronics in Agriculture, 73(2), 213-218. https://doi.org/10.5772/8006

Ruiz-Garcia, L., \& Lunadei, L. (2011). The role of RFID in agriculture: Applications, limitations and challenges. Computers and Electronics in Agriculture, 79(1), 42-50. https://doi.org/10.1016/j.compag.2011.08.010

Ruiz-Garcia, L., Barreiro, P., \& Robla, J. I. (2008). Performance of ZigBee-based wireless sensor nodes for real-time monitoring of fruit logistics. Journal of Food Engineering, 87(3), 405-415. https://doi.org/10.1016/ j.jfoodeng.2007.12.033

Ruiz-Garcia, L., Barreiro, P., Rodríguez-Bermejo, J., \& Robla, J. I. (2007). Monitoring intermodal refrigerated fruit transport using sensor networks: A review. Spanish Journal of Agricultural Research, 5(2), $142-156$. https://doi.org/10.5424/sjar/2007052-234

Ruiz-Garcia, L., Lunadei, L., Barreiro, P., \& Robla, I. (2009). A review of wireless sensor technologies and applications in agriculture and food industry: State of the art and current trends. Sensors, 9(6), 4728-4750. https://doi.org/10.3390/s90604728

Sarac, A., Absi, N., \& Dauzere-Peres, S. (2010). A literature review on the impact of RFID technologies on supply chain management. International Journal of Production Economics, 128(1), 77e95. https://doi.org/10.1016/ j.ijpe.2010.07.039

Sarac, A., Absi, N., \& Dauzère-Pérès, S. (2010). A literature review on the impact of RFID technologies on supply chain management. International Journal of Production Economics, 128(1), 77-95. https://doi.org/10.1016/ j.ijpe.2010.07.039

Shan, Q., Liu, Y., Prosser, G., \& Brown, D. (2004). Wireless intelligent sensor networks for refrigerated vehicle. Emerging Technologies: Frontiers of Mobile and Wireless Communication, 2004. Proceedings of the IEEE 6th Circuits and Systems Symposium on (Vol. 2, pp. 525-528). IEEE. https://doi.org/10.1109/CASSET. 2004.1321941

Sima, K., Syrovy, T., Pretl, S., Freisleben, J., Cesek, D., \& Hamacek, A. (2017). Flexible smart tag for cold chain temperature monitoring (pp. 1-5). 40th International Spring Seminar on Electronics Technology (ISSE), 2017, IEEE. https://doi.org/10.1109/ISSE.2017.8000996

Somashekhar, I. C., Raju, J. K., \& Patil, H. (2014). Agriculture Supply Chain Management: A Scenario in India. Research Journal of Social Science and Management, 4(07), 89-99. 
Thakur, M., \& Forås, E. (2015). EPCIS based online temperature monitoring and traceability in a cold meat chain. Computers and Electronics in Agriculture, 117, 22-30. https://doi.org/10.1016/j.compag.2015.07.006

Thakur, M., Sørensen, C. F., Bjørnson, F. O., Forås, E., \& Hurburgh, C. R. (2011). Managing food traceability information using EPCIS framework. Journal of Food Engineering, 103(4), 417-433. https://doi.org/ 10.1016/j.jfoodeng.2010.11.012

Thomas, V. M. (2008). Environmental Implications of RFID. IEEE International Symposium on Electronics and the Environment, May 19-22, 2008. https://doi.org/10.1109/ISEE.2008.4562916

Thompson, M., Sylvia, G., \& Morrissey, M. T. (2005). Seafood traceability in the United States: Current trends, system design, and potential applications. Comprehensive Reviews in Food Science and Food Safety, 4(1), 1-7. https://doi.org/10.1111/j.1541-4337.2005.tb00067.x

Ting, P. H. (2013). An efficient and guaranteed cold-chain logistics for temperature-sensitive foods: Applications of RFID and sensor networks. International Journal of Information Engineering and Electronic Business, 5(6), 1. https://doi.org/10.5815/ijieeb.2013.06.01

Tingman, W., Jian, Z., \& Xiaoshuan, Z. (2010). Fish product quality evaluation based on temperature monitoring in cold chain. African Journal of Biotechnology, 9(37), 6146-6151.

Trebar, M., Grah, A., Melcon, A. A., \& Parreno, A. (2011). Towards RFID traceability systems of farmed fish supply chain (pp. 1-6). 19th International Conference on Software, Telecommunications and Computer Networks (SoftCOM), 2011, IEEE.

Trebar, M., Lotrič, M., \& Fonda, I. (2015). Use of RFID temperature monitoring to test and improve fish packing methods in styrofoam boxes. Journal of Food Engineering, 159, 66-75. https://doi.org/10.1016/j.jfoodeng. 2015.03.007

Trebar, M., Lotrič, M., Fonda, I., Pleteršek, A., \& Kovačič, K. (2013). RFID data loggers in fish supply chain traceability. International Journal of Antennas and Propagation, 2013, Article ID 875973. https://doi.org/ $10.1155 / 2013 / 875973$

Twist, D. C. (2005). The impact of radio frequency identification on supply chain facilities. Journal of Facilities Management, 3(3), 226e239. https://doi.org/10.1108/14725960510808491

Wang, L., Kwok, S. K., \& Ip, W. H. (2010). A radio frequency identification and sensor-based system for the transportation of food. Journal of Food Engineering, 101(1), 120-129. https://doi.org/10.1016/j.jfoodeng. 2010.06.020

Wu, X., Wu, H., Xia, L., Ji, K., Liu, Z., Chen, J., ... Wu, Y. (2010). Socio-technical innovations for total food chain safety during the 2008 Beijing Olympics and Paralympics and beyond. Trends in Food Science \& Technology, 21(1), 44-51. https://doi.org/10.1016/j.tifs.2009.10.010

Yan, B., \& Lee, D. (2009, August). Application of RFID in cold chain temperature monitoring system. In Computing, Communication, Control, and Management, 2009. CCCM 2009. ISECS International Colloquium on (Vol. 2, pp. 258-261). IEEE. https://doi.org/10.1109/CCCM.2009.5270408

Zhang, J., Liu, L., Mu, W., Moga, L. M., \& Zhang, X. (2009). Development of temperature-managed traceability system for frozen and chilled food during storage and transportation. Journal of Food, Agriculture \& Environment, 7(3\&4), 28-31.

Zhang, Y., Cheng, R., \& Chen, S. (2018). Design of fresh food sensory perceptual system for cold chain logistics. In ITM Web of Conferences (Vol. 17, p. 03017). EDP Sciences. https://doi.org/10.1051/itmconf/20 181703017

Zhou, L., \& Chakrabartty, S. (2017) Self-powered Continuous Time-Temperature Monitoring for Cold-Chain Management. IEEE. https://doi.org/10.1109/MWSCAS.2017.8053064

Zou, Z., Chen, Q., Uysal, I., \& Zheng, L. (2014). Radio frequency identification enabled wireless sensing for intelligent food logistics. Phil. Trans. R. Soc. A, 372(2017), 20130313. https://doi.org/10.1098/rsta. 2013.0313 


\section{Notes}

Note 1. Since RFID sensor tags collect data using wireless communication, no PC connection is required.

Note 2. A very strict environment has to be built to simulate the practical situation for the link quality measurement.

Note 3. According to Jedermann et al. (2009), it takes five seconds to transfer recorded temperature values over the RFID interface.

\section{Copyrights}

Copyright for this article is retained by the author(s), with first publication rights granted to the journal.

This is an open-access article distributed under the terms and conditions of the Creative Commons Attribution license (http://creativecommons.org/licenses/by/4.0/). 